Ilona A. Meyer

\title{
Die rol van fokalisering as manipuleringstegniek in die produksie en resepsie van jeugverhale: die verhouding tussen volwasse outeur en jeugleser met spesiale verwysing na drie verhale van Dolf van Niekerk
}

\begin{abstract}
A survey of the research done in literature written specifically for adolescents, shows that remarkably little has been done to analyse the reception and production of such works. Those works, which touch on the suitability of adolescent literature, are rarely based on the principles of a literary-scientific approach. The reasons for this may lie in the fairly abstract nature of any literary work.

In this article an attempt is made to find some general guidelines which may be of relevance in the field of young adult reading. Using the works of a popular writer of Afrikaans books for adolescents, Dolf van Niekerk, the article focuses on the unique features of books for young readers, those aspects which distinguish this genre from adult literature, and the factors which make such works more acceptable to teenage readers.
\end{abstract}

\section{Inleiding}

'n Breë oorsig oor die literatuur wat raak aan jeugliteratuur, toon dat daar min inligting bestaan oor die resepsie en produksie van kinder- en jeugverhale. Werke wat wel handel oor die geskiktheid, al dan nie, van verhalende tekste vir jong lesers, is nie altyd literatuurwetenskaplik gefundeer nie. 'n Werklik empiriese ondersoek is moeilik oor 'n onderwerp wat so veel met die 
menslike psige te doen het. Tog is dit moontlik om vanuit 'n goed gefundeerde teoretiese raamwerk sekere algemene afleidings te maak wat moontlik toegepas kan word in 'n studie van kinder- en jeugliteratuur.

Die gekompliseerdheid van jeugliteratuur blyk reeds uit bepaalde misvattinge daaroor, naamlik dat dit nie literatuur is nie omdat dit nie so eksplisiet (soos bv. die Sestigers se werk) tot die intellek spreek nie. Henry James se uitsprake teen die neëntiende eeu aangaande die intellek wat gestimuleer word, is weer in kontras met Fadiman se standpunt: "But we must not be too quick to pass from the dimension of length and breadth to that of depth and say that children's books can never be as deep. The child's world is smaller than the grownup's; but are we so sure that it is shallower?" (aangehaal deur Steenberg, 1986:3).

Alhoewel hierdie stelling gemik is op kinderliteratuur, bring dit ook die kwessie van hoe jeugliteratuur daar uitsien na vore. Die feit dat bitter min oor jeugliteratuur geskryf is, dui op 'n onderskatting van dié terrein wat tussen kinder- en volwasseneliteratuur geplaas kan word.

By nadere ondersoek blyk dit belangrik te wees om die genre jeugliteratuur verder te omskryf deur die volgende vrae te beantwoord:

(i) Wat is die unieke kenmerke van jeugliteratuur,

(ii) hoe word dit van volwasseneliteratuur onderskei en

(iii) wat maak dit aanvaarbaar en geskik vir die adolessent?

\section{Jeugliteratuur - 'n nadere beskouing}

Die idee is dat die boek daardie patroon van lewe moet kan reflekteer wat eie is aan die adolessent. "Reading literature is suddenly meeting ourselves, encountering situations similar to our own, rediscovering our own emotions and relationships" (Varlejs, 1978:11). Dit moet aan die tiener kan toon hoe om uit allerlei krisisse te beweeg na aanvaarde sosiale norme (Varlejs, 1978:76). Die outeur moet dus kennis neem daarvan dat sodanige krisisse juis veroorsaak kan word deur die verskille tussen die ervaringsveld van die tiener en die volwassene se idee van aanvaarde sosiale gedrag.

Hierdie argument plaas die fokus op die primêre kriterium vir adolessentliteratuur, naamlik dat die hoofkarakter 'n adolessent moet wees. Vanweë dié feit sal die adolessente leser hom met die gebeure rondom die hoofkarakter kan identifiseer.

\subsection{Die hoofkarakter as adolessent-fokalisator}

Die gemiddelde ouderdom vir die sentrale karakter in 'n adolessentnovelle is ongeveer 15 jaar. Die hoofsaak is dat die protagonis beskou moet word in sy 
definiëring van sy wêreld en sy verhouding daarmee, wat afhanklik is van sy chronologiese, emosionele en biologiese rypheid (Mertz, 1983:120).

Die primêre kriterium vir adolessentliteratuur, naamlik die adolessent as protagonis, dwing die outeur om die fokus op die sentrale karakter in die verhaal te plaas. 'n Tiener moet dus die fokalisator in die verhaal wees, ongeag wie die verhaal vertel. Genette het veral die verwarring wat daar bestaan oor "point of view" onder die loep laat kom met sy definitiewe onderskeid tussen wie sien? en wie vertel? in 'n verhalende teks. Dit kom neer op 'n onderskeid tussen 'n verteller enersyds en 'n fokalisator andersyds. Die vertelling moet uit die jeugdige se perspektief wees, die een wat sien dus, al vertel hy nie self nie. Hierdie onderskeid tussen die een wat vertel en die een wat sien, kom duidelik na vore in twee van die werke onder bespreking.

In Die haasvanger is Lourens (wie se bynaam Kiewiet is) die fokalisator maar hy is nie self die verteller nie, teenoor Albert in Skrik kom huis toe wat as verteller-fokalisator ook self aan die woord is. In die geval van Albert is hy dus die verteller- fokalisator omdat hy vertel én sien.

In Skrik kom huis toe is dit opvallend hoedat die sintuie van Albert uit 'n jeugdige se perspektief benut word. Hy sien die kleinste detail: 'n konstabel wat hy vreesbevange nader, word soos volg gesien: "Daar is blink knope op sy bors ... Die yslike blink boeie hang byna onder sy arm ... 'n Blink wapen voor sy pet, 'n blink lyfband" (12). Sy reuksintuig word ook benut in die kosreuke en die reuk van sy stiefma - "soos wildeals" (61). Sy tassin word ook in sy verhoudings met die volwassenes benut: "Omdat hy lief is vir Ma-Bet, verlang hy om aan haar arm te vat" (57). Sy wens om fisieke kontak met sy pa te maak, is 'n weerspieëling van die liefdelose houding van sy pa en sy hunkering na dié aanraking om bevestiging van sy pa se liefde te ontvang.

Alhoewel Lourens, alias Kiewiet, in Die haasvanger nie self aan die woord is en dus nie as verteller optree nie, word die verhaalgebeure vanuit sy perspektief vertel. Die verteller se blik rus op alle objekte in die verhaal waarmee Lourens in verhouding is. Die alwetendheid van die verteller in die verhaal sluit in 'n "geheel van objecten, schouwspel waarop de blik blijft rusten en heeft betrekking op het object van de visie" (Dembinski, 1979:217). In dié geval is dit Lourens se visie wat vooropgestel word. Die verhaal word vertel soos hy die objekte, mense en ruimte beskou. Die verteller in die verhaal beweeg met die fokalisator. 'n Illusie van onmiddellikheid word deur hierdie fokalisering bewerkstellig: die sintuie van die fokalisator word op die moment van waarneming deur die verteller benut. Alhoewel daar flitsende momente is waar ander karakters se gedagtes en gevoelens kortstondig uitgebeeld word, bly die fokus op die karakter van Lourens. In sodanige gevalle dien die weerspieëling, byvoorbeeld van die onderwyser en die vriendin se gevoelens, as beligtende faktore op die effek van fokalisering in die verhaal en word dit nie deur die leser as 'n breuk in die momentum van die verhaal ervaar nie (45 en 55). 
Al bevind die tienerleser hom nie in dieselfde omstandighede as die protagoniste in bogenoemde verhale nie, is daar genoeg van die essensie van grootword in die ervaringe van almal sodat die tienerleser homself daarmee kan identifiseer.

\subsection{Posisionering van die verteller}

Dit is belangrik dat daar ' $n$ narratiewe instansie moet wees wat die verhaal vertel. ' $n$ Verteller hoef nie self die gebeure waaroor hy vertel te ervaar nie - in so 'n geval staan hy dan buite die fiktiewe verhaalgebeure. Genette noem dié geval waar die verteller afwesig is van die storie heterodiëgeties en waar die verteller 'n karakter in die verhaal en dus aanwesig is homodiëgeties (1980:245).

Volgens Genette (1980:244) lê die outeur se keuse tussen een van die volgende: om die storie deur een van die karakters te laat vertel of om dit deur 'n verteller buite die storie te laat vertel.

Albert Muller in Skrik kom huis toe is self aan die woord in die verhaal en tree dus as homodiëgetiese verteller op. Ongeag die aard van die verteller, bly die protagonis en fokalisator as adolessent die kern van die toeganklikheid van die verhaalgebeure vir die adolessente leser. "Focus on a single adolescent is the norm and typically, that one character's voice and perspective frame the story" (Mertz, 1983:120).

Beide die grammatikale derdepersoonverteller in Die Haasvanger en die eerstepersoonvertellers in Karel Kousop en Skrik kom huis toe is 'n weerspieëling van die gedagtes en gevoelens van die adolessent as protagonis. Hierdeur word 'n kommunikatiewe funksie in verhouding met die adolessente leser verrig. Die gekonsentreerdheid op 'n fokalisator in die adolessentverhaal bring 'n eenvoud mee wat direk tot die adolessente leser spreek.

\subsection{Eenvoud en direktheid}

In al drie verhale van Dolf van Niekerk kan die adolessente leser die aanbieding volg vanweë die feit dat die aanbiedinge op eenvoudige en chronologiese wyse op die adolessent as protagonis gerig is. Alle gebeure word hoofsaaklik deur die fokalisator beleef. Sy verhoudings ten opsigte van die ander karakters (bv. sy ouers of ander volwassenes) en die verwerking van situasies waarin hy hom in sy leefwêreld bevind, spreek van 'n ongekompliseerde direktheid: "Central characters are shown confronting the realities of their world directly and responding with equal directness" (Mertz, 1983:121). Gebeure word normaalweg op chronologiese wyse so aangebied dat die leser gedurig die verhaalgebeure deur die oë van die adolessent-fokalisator, ofte wel protagonis, beleef. Gebeure waarin die fokalisator nie aktief betrokke is nie word nie breedvoerig beskryf nie.

Fokalisering word as manipuleringstegniek gebruik in dié sin dat die verhaal 
geproduseer is vanuit die perspektief van die adolessent, met ander woorde hoe hy aspekte en objekte in sy betekeniswêreld op psigiese en fisiese vlak sien. Hierdie siening van fokalisering word ondersteun deur Mieke Bal as sy beweer: "Focalisatie is ... volgens mij het belangrijkste, meest indringende en meest subtiele manipulatiemiddel" (1985:122).

\subsection{Strukture en konvensies}

Daar is gewoonlik 'n effense verandering in die protagonis se lewe wat bepalend is vir die handelinge in die storie. Dit word gekenmerk deur 'n verandering in die gesinstruktuur, 'n nuwe portuur-verhouding en moontlike bande met die teenoorgestelde geslag. In die drie verhale onder bespreking gee die verandering in familiekonvensies aanleiding tot nuwe gedragspatrone en gevolglike intriges by die adolessent.

Lourens (Die Haasvanger) besef in sy laaste skooljaar dat dinge in die huwelik van sy ouers onherstelbaar is. Hy deurloop 'n pynlike inisiasieperiode maar ontwikkel tot 'n verantwoordelike mens (Iskemus, 1986:18). Albert Muller (Skrik kom huis toe) is 'n vereensaamde kind met probleemouers. Sy gemoedskrisis wat deel van die intrige van die verhaal uitmaak, hou verband met sowel sy verhouding tot sy ouers as met sy duiwe, maar teen die einde kom ook hy tot 'n beter begrip van die lewe.

In die hedendaagse samelewing is egskeidings en allerlei gesinsprobleme aan die orde van die dag. Dit is aspekte van die lewe waarmee die adolessent worstel en wat hy dikwels self probeer oplos omdat hy 'n behoefte aan 'n stabiele en ongekompliseerde gesinslewe het. Vir die adolessent is die behoefte om oor dié probleme te lees betekenisvol; hierin kan hy oplossings vind vir sy probleme en so 'n boek kan as biblioterapie dien. "Geskikte leesstof kan veroorsaak dat die behoeftes kleiner word. Dit kan selfs dien om sekere behoeftes tydelik te laat verdwyn" (Lohann, 1985:48).

\subsection{Hoofkarakters toon onafhanklike denke en handeling}

Volgens Mertz \& England (1983:121) word die hoofkarakters nie gedra of gelei deur portuurgroepe nie. Hulle werk self hul probleem uit ongeag of dit die verwerking van die dood van 'n ouer, 'n egskeiding, 'n verhouding met die teenoorgestelde geslag, morele of etiese of beide dilemmas is. Die hoofkarakters, ofte wel fokalisators, in Dolf van Niekerk se verhale hier onder bespreking, is bewyse hiervan.

Albert in Skrik kom huis toe verkeer in 'n stryd deurdat hy die dood van sy moeder het om te verwerk asook die antagonisme van sy vader vanweë sy stiefma se houding jeens hom: dit is duidelik dat sy vader hom tug op haar aandrang. Hy neem gewoonlik sy toevlug tot sy duiwe en bring hele dae daar deur - hulle word die ankers in sy lewe. Een spesifieke aand gebeur dit dat sy vader hom "vier houe (slaan) wat brand en opswel" (10). 
Lourens bevind hom in 'n soortgelyke situasie in Die Haasvanger - hy moet die koudheid van sy ma as 'n verbitterde en afgesloofde vrou verwerk. Hy moet gedurig gebuk gaan onder haar emosionele uitbarstings: "Ek is niks anders as jul voetvel nie! Ek is moeg getrap - moeg, verstaan jy?" (22). Dit is soos Mertz \& England dit stel ten opsigte van die stryd waarin die adolessent as fokalisator in sy alleenheid hom bevind:

Most novels portray the adolescent as being alone in trying to confront life's problems; a sense of isolation, even abandonment by others, fills many of the plots. (1983:121)

Dit is die adolessent wat uitreik na die volwasse wêreld eerder as andersom. Dit hang saam met die adolessent se rypwording en gepaardgaande onafhanklikheidswording. Bande word dan gewoonlik met 'n persoon wat geen familiebetrekkinge met die adolessent het nie, gesmee. In Lourens se geval is daar Janet, die klasmaat vir wie hy lief is en sy onderwyser, meneer Fick, wat 'n belangrike rol in sy atletiekloopbaan speel. So ook is daar in Albert se geval Ma-Bet "wat al die dooies op die dorp uitlê en wat snags siekes oppas" (21). Sy verhouding met haar word onontbeerlik, want met haar ruimhartigheid gee sy hom die liefdevolle aandag en begrip wat in sy ouerhuis ontbreek.

Die adolessent se behoefte aan aanvaarding en liefde word op dié wyse bevredig. Die tydperk word gekenmerk deur die ontwikkeling van die eerste liefdesverhoudings of ' $n$ aanduiding dat daar 'n belangstelling in die teenoorgestelde geslag is. Lourens (Kiewiet) is op 'n onsekere wyse lief vir Janet: "Daar is 'n nuwe soort opgewondenheid in hom. Hy ken die lê van 'n haas, die opstaan van 'n haas en baie ander dinge wat rondom die dassiekrans lewe, maar dié brief is iets anders" (55) - na aanleiding van 'n brief van Janet. Vir Kiewiet is Janet en die dassiekrans belangrik. Net die aanraking van hul skouers gedurende die rit na die atletiekbyeenkoms het hom met 'n rustige opgewondenheid gevul. "Kiewiet woon tussen Janet en die dassiekrans. Kiewiet rus" (60).

\subsection{Die gevolge van besluitneming}

Gedurende hierdie fase moet die adolessent bewus gemaak word van die gevolge van sy dade. In menige adolessentnovelles word hulle so uitgebeeld dat lesers kan sien dat besluite wat geneem is aanleiding gee tot die saamleef met die gevolge daarvan.

Daar bestaan ook ' $n$ behoefte by die adolessent om op realistiese wyse aangaande die onderskeiding tussen goed en kwaad ingelig te word. Gans (1970:129) beveel aan dat temas wat 'n uitdaging vir die gewete is en waar 'n keuse uit menslike waardes gemaak moet word, soos byvoorbeeld tussen reg en verkeerd, geregtigheid en ongeregtigheid, ideaal in die behoefte van die adolessent voorsien.

Ten spyte van die feit dat Albert se stiefma nie die duiwe op die werf wil hê 
nie, gaan hy voort om hulle aan te hou. Hy bestee soveel tyd by en met die duiwe, dat hy laat is vir sy etes. Sy dade word bestempel as ongehoorsaamheid. Albert se stiefma wil hom vanweë sy ongehoorsaamheid laat wegstuur en selfs sy pa vind die situasie onhoudbaar: "Na die duiwel met die duiwe! Jy het al genoeg sonde en ergernis met die goed veroorsaak! As hulle die oorsaak van jou ongehoorsaamheid is, dan loop ek nou en smyt hulle uit die hok!" (55).

Wanneer Lourens besluit om vir die skool te hardloop, besef hy die gevolge van dié besluit. Hy het nog altyd in die veld gehardloop, maar nou moet hy geld verdien om sy atletiekuitrusting en reisgeld te kry. Lourens aanvaar dus die verantwoordelikheid om geld te verdien sodat hy by sy besluit om 'n atletiekloopbaan te volg, kan bly.

In Karel Kousop besluit Gerrit in een geval om vir sy pa 'n leuen te vertel. Omdat hy egter besef dat die gevolge van sy leuen verskriklik kan wees indien sy pa uitvind, hinder dit hom: "Dit pla my dat ek vir my pa gelieg het" (49), en later: "... miskien is ek bang ek verdwaal oor die leuen wat ek vertel het" (50). Hierdie skuldgevoel is deel van die ontwikkeling van 'n besef dat alle besluite gevolge dra.

\section{7 'n Bewustheid van die adolessent se ontwikkeling}

Die bewuswording van die adolessent as ontwikkelende wese lei na die eksplorering van die fisiese, psigologiese en sosiale verandering waardeur dié fase gekenmerk word. Seksuele ontwaking kan as 'n tema in adolessentfiksie beskou word (Mertz \& England, 1983:122). In Lourens se handelinge is daar dié ontwaking te bespeur. $\mathrm{Hy}$ is bewus van 'n meisie, Janet, wat groot belangstelling in sy naellope toon en self die wenbeker opvryf, maar hy is nog onseker oor die gevoel wat hy vir die eerste keer ervaar: "Haar oë trek syne aan. Dit duur 'n ewigheid voor hy toegee en nog langer om weg te kyk en onder die pawiljoen in te hardloop" (73).

Samehangend hiermee is daar gedurende hierdie fase 'n geleidelike toename in besorgdheid oor voorkoms en die gepaardgaande aanvaarding: "The adolescent's great absorption with appearance is an understandable and unfortunate result of a society which overemphasizes physical attractiveness" (Mertz, 1983:7). Alhoewel daar in Die haasvanger wel sprake is van hierdie bewuswording in die selfbewustheid van die sentrale karakter in die teenwoordigheid van die meisie, Janet, word minimale aandag hieraan geskenk in die ander twee werke. Gerrit in Karel Kousop is byvoorbeeld te veel aan die aarde gebonde en die liefdestema kom dus glad nie in die gedrang nie.

\section{8 'n Weerspieëling van maatskaplike gesindhede en aangeleenthede}

Adolessentnovelles verkry relevansie wanneer dit kontemporêre probleme aanraak. Aspekte soos egskeiding, swangerskap en verdowingsmiddels was 
nog altyd taboe. In die Amerikaanse gemeenskap het hierdie aangeleenthede egter prominensie verkry. In Die Haasvanger en Skrik kom huis toe is relevante temas wel ter sprake omdat Albert in Skrik kom huis toe byvoorbeeld bewus is daarvan dat sy moeder by sy geboorte gesterf het en vanweë die feit dat hy die vyandskap van sy stiefmoeder in haar aanrandings (kindermishandeling) ondervind. Lourens in Die haasvanger word algaande bewus van die verwydering tussen sy ouers - totdat hy sy pa by 'n ander vrou sien. In Karel Kousop is Karel se vader 'n moordenaar. Dit is ironies dat Gerrit se vader juis Karel se pa gevange neem en die seuns se bestaan hierna soos volg is: "Drie nagte lê ons wakker sonder om iets te sê. Af en toe sluimer ons in. Dié ding van Karel se pa is so groot dat 'n mens dit nie uit jou gedagtes kan stoot nie" (74). Soos Mertz dit stel: "While adolescent fiction deals with current issues, in most instances the books reinforce the status quo" (1983:7). Daar word dus gewoonlik aanvaarde norme voorgehou.

Sodanige kontroversiële onderwerpe kom baie relevant voor in jeugliteratuur en is dus meer aanvaarbaar vir die adolessente leser. Op dié manier leer hulle om die volwasse wêreld te verstaan en word hulle daarop voorberei. Vir Gertie Evenhuis is die volgende belangrik in dié opsig dat die adolessente leser voorberei word: "In al mijn boeken zijn de verhoudingen tussen ouders en kinderen, tussen grootouders en kinderen, tussen kinderen onderling belangrijk en beschrijvenswaard omdat ze ook in het leven van zo grote invloed zijn" (Van den Hoven, 1980:60). Selfs Miep Diekman wat in 1970 die Nederlandse staatsprys vir kinder- en jeuglektuur ontvang het, se boeke raak kwessies soos nasionalisme, konserwatisme en rassisme aan (Van den Hoven, 1980:286). Sy is ook die mening toegedaan dat daar oor realiteite geskryf moet word. Daarom het sy besluit om die rigting van die harde werklikheid te kies: "Als een meisje op haar twaalfde jaar verkracht kan worden moet zijn dan wachten tot zijn volwassen is eer zij erover lezen mag? Waar kan een jongere, die twijveld of hij of zij homoseksueel is, veilig met zijn vragen heen? ..." (1980:287).

Met hierdie realiteite kan die adolessent hom identifiseer en dit sal vir hom die moeite werd wees om te lees sodat hy moontlike hanteringsvaardighede vir sy probleme kan kry. Lesser (1981:13) verwys na "analogizing" waardeur die kind die situasie in die boek met sy eie vergelyk sodat sy angs verminder deurdat hy sien hoe die probleem oorkom word.

\subsection{Rypwording in die sentrale karakter}

Vanweë die adolessent se ondervindinge kan hy later beter in die grootmenswêreld aanpas. 'n Mens let op dat die adolessentkarakter ryper is teen die einde van die novelle as wat hy aanvanklik was.

In Die haasvanger word Lourens se onafhanklikheid duidelik namate die verhaal ontplooi: vanaf ' $n$ haasvanger wat tussen huis, skool en die lêplek van hase beweeg het, tot 'n naelloper wat sy skool op plekke weg van die huis 
moet verteenwoordig. In Karel Kousop word Gerrit en Karel geleidelik verantwoordelikhede gegee soos die skeer van skape en die melk van koeie. Hulle weet hulle moet verantwoording doen indien iets verkeerd gaan, maar hulle is trots op die mate waarin hulle vertrou word om hul take reg te doen.

In volwasseneliteratuur is daar dikwels sentrale karakters wat teen die einde van die verhaal ten volle tot inkeer of insig kom - die meeste adolessentnovelles het 'n aanduiding dat die sentrale karakter verander het, maar daar is aanduidinge dat vordering nog sal plaasvind, wat dui op 'n wordingsproses in dirckte relasie met sy spesifieke leeftyd (Grové \& Botha, s.j.:54).

Daar word soms van die adolessent verwag om soos 'n volwassene op te tree, maar hy het 'n gebrek aan ondervinding, kennis en rypheid. In sy strewe na volwassenheid is hy betrokke in 'n ontwikkeling van sy eie identiteit. Ten einde laasgenoemde te bereik, moet hy 'n aantal ontwikkelingstake bemeester of uitvoer. Volgens Erikson (1968:396) kom die adolessent voor 'n identiteitskrisis te staan wat hy slegs te bowe kan kom indien hy die ontwikkelingstake bemeester. Die antwoorde oor hoe om sy ontwikkelingstake te bemeester, kan hy in boeke vind. "The idea that books may contain characterbuilding elements for youth, sometimes called developmental values, has now become an accepted concept" (Hanna, 1960:54).

Die fokalisators in die verhale word in krisissituasies geplaas en wat van belang is, is hoe hulle in hierdie moeilike situasies optree om die struikelblokke te bowe te kom. Kiewiet (Lourens) weet dat hy die verwydering tussen sy ouers vir homself moet uitmaak voordat hy sy gedagtes by sy atletiekloopbaan kan bepaal. "Kiewiet is nouliks van die ander atlete bewus. Sy ma en pa en die vrou van Boskop is by hom en Ou Boel en die res van die wêreld bestaan nie. Daar is iets wat hom dryf - 'n ding wat hy vreeslik vinnig moet oplos voor hy sal kan hardloop" (83).

\section{Leesbelangstelling by die tiener}

Indien 'n teks nie aan die adolessente leser se leesverwagtinge voldoen nie, kan hy leesbelangstelling verloor. Volgens Hanna (1960:46) word die kind se leesaktiwiteite teen ongeveer die ouderdom van 15 jaar vanweë skool, tuiswerk, buitemuurse aktiwiteite en sosiale bedrywighede minder. Terselfdertyd moet in ag geneem word dat baie adolessente nie die behoefte het om te lees nie. Chambers het 'n studiegroep tussen die ouderdomme 11 en 17 geneem om uit te vind waarom daar so 'n traagheid om te lees bestaan. Redes is dat i) hulle nie van verhale hou nie, ii) hulle nie tyd het nie, iii) die tienertyd ' $n$ tyd is vir groepaktiwiteite en nie vir lees nie en iv) die beeldradio en films die tyd in beslag neem wat normaalweg aan leesgewoontes bestee word (1969:5). Volgens Die Burger van 5 Mei 1987 kyk kinders van standerd 3 tot matriek 21 uur per week televisie. Dit is egter moontlik dat indien adolessente die nodige leiding kry en boeke beskikbaar is wat hulle interesseer, leeslus in hulle aangewakker sal word. Hierna kan die invloed van die portuurgroep 
gebruik word om soveel moontlik ander lesers betrokke te kry. 'n Gebrek aan leesstof wat voldoen aan die adolessent se behoeftes is een van die vernaamste faktore wat tot traagheid in lees lei. Daarom is dit noodsaaklik dat dié faktore by die produksie van 'n tienerteks in ag geneem moet word.

Die adolessent moet sy behoeftes deur die lees van 'n boek bevredig kan kry, indien sy belangstelling eers gaande gemaak kan word. Hierdie behoeftes soos hierbo aangedui, is gefundeer in lewensituasies waarop hy sy fokus plaas. Dus is die jeugverhaal met ' $n$ adolessent as fokalisator waarin daar op die betekeniswêreld van 'n adolessent gefokaliseer word, die antwoord. Dr. R. Carlsen van die Universiteit van Iowa stel dit onomwonde: "That is why, when the upper-grade pupils give their reasons for naming a particular book as the work which they liked most of all, they write first of all about what they learned about life from having read it" (Kijoth, 1970:324). Hulle leer dus die meeste uit die gefokaliseerde wêreld soos 'n adolessent die realiteite sien.

\section{Veranderende norme by die resepsie}

Die teks tree as funksie van die geskiedenis op - namate ons horisonne verander, word 'n teks ook daarvolgens verstaan. Die teks is nie konstant in betekenis nie, maar word in sy wording verstaan soos ons binne tydkonteks betekenis daaraan gee. "The horizon in which it first appeared is both different from our own and a part of our own in that it is temporarily distant from, yet constitutive of the present horizon" (Holub, 1984:149).

'n Literêre werk wat deur een groep kontemporêre lesers aanvaarbaar gevind word, mag die teenoorgestelde uitwerking op lesers van die toekoms hê. Hierdie aspek is van kardinale belang vir die leesverwagtinge wat deur die adolessent in ons kontemporêre samelewing gekoester word. Veral met die oog op 'n moontlike toekomstige nie-rassige samelewing moet die soeklig ten opsigte van leesverwagtinge, ofte wel verwagtingshorisonne, geplaas word op jeugliteratuur in die algemeen en Afrikaanse jeugliteratuur in die besonder.

'n Studie van 1500 Afrikaanse kinder- en jeugboeke wat van 1897 tot 1982 gepubliseer is, het betekenisvolle inligting na vore gebring (Tötemeyer, 1985). Alhoewel aanvaar word dat daar 'n gaping tussen literatuur en eksterne werklikhede bestaan, sodat eersgenoemde nie net as 'n spieëlbeeld van laasgenoemde beskou moet word nie, moet jeugliteratuur se vormingswaarde en oplossings vir die adolessent se bemeestering van sy ontwikkelingstake steeds in die oog gehou word.

Dolf van Niekerk slaag in Karel Kousop uitmuntend daarin om besondere vriendskapsbande tussen twee seuns met verskillende kultuur-agtergronde te illustreer. Die seuns se lewens loop saam vanweë omstandighede. Karel, die skaapwagtertjie, se ma het hom ingeboek by Gerrit-hulle waar hulle groot maats word. Daar word uitgebeeld hoe hulle mekaar se leed deel, saam swem en in dieselfde kamer slaap. 
Van Niekerk se ander twee verhale, Die Haasvanger en Skrik kom huis toe, slaag na my mening nog beter daarin om vir die tiener leesstof in 'n eventuele nie-rassige samelewing te verskaf; temas wat vir alle adolessente seuns geldig is, ongeag kleur, status of klas word aangebied. Dit is interessant dat Skrik kom huis toe alreeds in 1968 sy verskyning gemaak het en dat die norme wat gedurende daardie tyd gegeld het in 1986 steeds geldig is ten opsigte van die verwagtingshorison van die tienerleser. (Die herdruk daarvan dui op 'n volgehoue aanvraag daarvoor.) Vanweë die versmelting van die horison van die leser aan die een kant en die teks aan die ander kant, kan die tienerleser hom met gebeure daarin identifiseer. Sodoende bied dit oplossings vir die ontwikkelingstake wat hy moet bemeester.

\section{Gevolgtrekking}

Waar die adolessent as ontwikkelende leser en ontvanger van jeugverhale deur die outeur in ag geneem word, sal die adolessent se lees- en ervaringsrepertorium in die skryf van die literatuur voorop gestel word.

Indien fokalisering lewensgetrou is, is so 'n verhaal nie gebonde aan tyd nie en sal dit tydloos aan die verwagtingshorison van werklike lesers voldoen. Die gewildheid van Skrik kom huis toe vanaf 1968 tot 1986 is 'n goeie voorbeeld hiervan. 'n Novelle soos Die haasvanger sal met sy betroubare immanente verteller die adolessente leser van die platteland aanspoor tot prestasie én ontvlugting aan die stadstiener kan bied. Die adolessente leser, ongeag status, sal met die fokalisator kan identifiseer.

Alhoewel daar in Karel Kousop van twee verskillende kulture sprake is, sal identifisering met die karakters nie problematies wees nie, want beide Gerrit en Karel is tipiese adolessente wat in hul kwajongstreke nie verstrengeld raak met vooropgestelde idees omtrent mekaar nie.

Die essensie van skryf vir adolessente lê dus in 'n aanbieding vanuit die perspektief van die adolessent en nie die van die outeur nie. Om realistiese fiksie te kan skryf, moet die outeur 'n aanvoeling vir die leefwêreld van die adolessent hê oor wie en vir wie hy skryf. 'n Volwasse outeur in 'n kultureel uiteenlopende samelewing wat byvoorbeeld nie die leefwêreld van die verskillende adolessente verken het nie, sal nie multikulturele situasies kan uitbeeld nie.

\section{Bibliografie}

American Library Association. 1980. Young Adult Literature, Background and Criticism. Chicago.

Bal, M. 1985. De theorie van vertellen en verhalen. Muiderberg: Couthino.

Chambers, Aidan. 1969. The Reluctant Reader. Oxford: Pergamon Press.

Dembinski. J. 1979. Narratologie: tekstbeschryving zonder criteria. Spectator 9(3): 208-221.

Erikson. Erik H. 1968. Identity: Youth and Crisis. London: Faber.

Gans, Roma. 1970 In: Kujoth, J.S. Reading Interests of Children and Young Adults. Metuchen, N.J.: The Scarecrow Press. 
Genette. G. 1980. Narrative Discourse. Oxford: Basil Blackwell.

Grové, A.P. en Botha. E. s.j. Handleiding by die studie van die letterkunde. Kaapstad: Nasou. Hanna, G.R. 1960. Books, Young People and Reading Guidance. New York: Mc Allister, Harper \& Row.

Holub. Robert C. 1984. Reception Theory: A Critical Introduction. The New Action Series. Methuen: New York.

Iskemus. 1986. Ongepubliseerde aantekeninge. Stellenbosch: Universiteit van Stellenbosch.

Kujoth, J.S. 1970. Reading Interests of Children and Young Adults. Metuchen, N.J.: Scarecrow Press.

Lesser, S.O. In: Heather, P. 1981. Occasional Papers No.6. Young People's Reading: A Study of the Leisure Reading of Thirteen to Fifteen Year Olds. Crus. Sheffield.

Lohann, Carl. 1985. Kinderlektuur en biblioterapie. Literator 6(2):46-53.

Mertz. Maia Pank \& England, David A. 1983. The Legitimacy of American Adolescent Fiction. School Library Journal. Morgentown.

Steenberg, E. 1979. Kinderverhale van ses tor twaalf: Reuse-blokboeke. Kaapstad: Academica.

Steenberg, E. 1986. Misvattings oor kinderboeke. Klasgids 21(1): 3-5.

Tötemeyer, A-J. 1985. Afrikaanse kinderlektuur as literatuur in 'n veelrassige samelewing. Literator 6(2):66-85.

Van den Hoven, Pieter. 1980. Achter de keukendeur. Zestien gesprekken over jeugdliteratuur. s'-Gravenhage: BZZTOH.

Van Niekerk. Dolf. 1985. Karel Kousop. Kaapstad: Tafelberg.

Van Niekerk, Dolf. 1985. Die haasvanger. Kaapstad: Tafelberg.

Van Niekerk, Dolf. 1986(vierde druk). Skrik kom huis toe. Kaapstad: Tafelberg.

Varlejs, Jana. 1978. Young Adult Literature in the Seventies, A Selection of Reading. Metuchen, N.J.: The Scarecrow Press. 